\title{
Solid state stability and solubility of triethylenetetramine dihydrochloride
}

Théo Henriet, ${ }^{1}$ Inès Gana, ${ }^{2}$ Carine Ghaddar, ${ }^{3}$ Maria Barrio, ${ }^{4}$ Yohann Cartigny, ${ }^{5}$ Najet Yagoubi, ${ }^{1}$ Bernard Do, ${ }^{1,3}$ Josep-Lluis Tamarit, ${ }^{4}$ Ivo B. Rietveld ${ }^{6}$

${ }^{1}$ Matériaux et Santé (EA 401), Faculté de Pharmacie, Université Paris Sud, 5, Rue Jean-Baptiste Clément, 92296, Chatenay-Malabry, France

${ }^{2}$ Laboratoire de chimie analytique, Faculté de Pharmacie, Université de Monastir, rue Ibn Sina, 5000 Monastir, Tunisie

${ }^{3}$ Etablissement Pharmaceutique de l'Assistance Publique-Hôpitaux de Paris, Agence Générale des Equipements et Produits de Santé, 7, rue du Fer à Moulin, 75005 Paris, France

${ }^{4}$ Grup de Caracterització de Materials (GCM), Departament de Física, Universitat Politècnica de Catalunya, ETSEIB, Diagonal 647, 08028 Barcelona, Spain

${ }^{5}$ Normandie Université, UR, Laboratoire SMS, EA 3233, Crystal Genesis Unit, IMR 4114, F-76821 Mont Saint Aignan Cedex, France

${ }^{6}$ Caractérisation des Matériaux Moléculaires à Activité Thérapeutique (CAMMAT), Faculté de Pharmacie, Université Paris Descartes, 4, avenue de l'Observatoire, 75270 Paris cedex 06, France 


\section{Abstract}

The API triethylenetetramine dihydrochloride used as an alternative treatment of Wilson's disease is sensitive to water and it exhibits polymorphism. As this may become an issue for the drug formulation, the physical stability has been studied by differential scanning calorimetry, highpressure thermal analysis, dynamic vapor sorption, and X-ray diffraction as a function of temperature. In addition, high-pressure liquid chromatography and mass spectrometry have been used to study the purity and chemical stability of the API. A pressure-temperature phase diagram of the pure compound has been constructed and it can be concluded that form II is monotropic in relation to form I, which is the only stable solid. The solubilities of the different solid forms have been determined with the help of a temperature - composition phase diagram. The API is very soluble, at $20^{\circ} \mathrm{C}$ about $10 \%$ of the saturated solution with respect to the dihydrate consists of API and the solubility of the pure form I is twice as high. Moreover, it has been shown that at $20^{\circ} \mathrm{C}$, a relative humidity above $40 \%$ induces the formation of the dihydrate and at $70 \%$ a saturated solution appears. At higher temperatures, the formation of the dihydrate appears at lower relative humidity values. A clear link has been established between the API's chemical stability, its physical stability and the relative humidity in the air. Humidity levels above $40 \%$ are detrimental to the quality of the API. 


\section{Introduction}

The dihydrochloride salt of triethylenetetramine, 1,2-ethanediamine, $\mathrm{N}, \mathrm{N}^{\prime}$-bis(2-aminoethyl) is a polyamine chelator of copper (II) (Figure 1). It is currently used as an alternative to D-penicillamine to treat Wilson's disease. ${ }^{1}$ Moreover, due to its activity on copper homeostasis triethylenetetramine dihydrochloride (TETA.2 $\mathrm{HCl}$ ) is being tested for numerous applications such as treatments for internal organ damage in diabetes patients, ${ }^{2}$ Alzheimer's disease, ${ }^{3}$ and even cancer. ${ }^{4}$
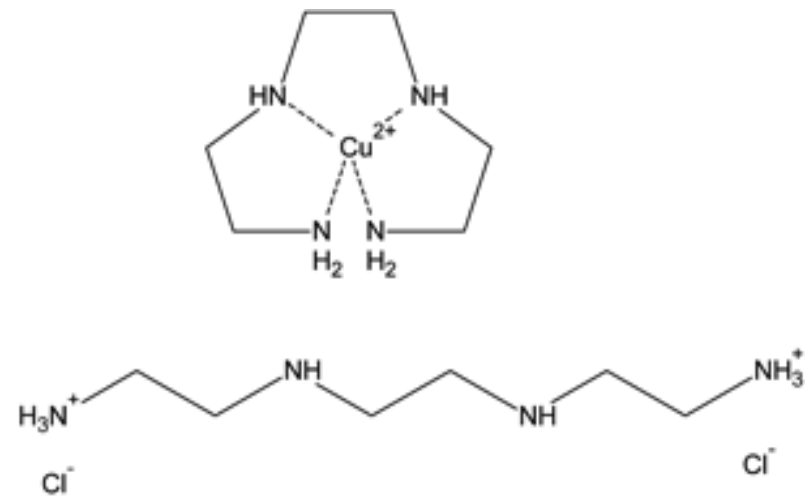

Figure 1 Chemical structure of triethylenetetramine dihydrochloride (bottom) and the TETA-Cu complex (top)

Understanding of the physicochemical stability of TETA.2HCl is important for its drug development. First, the crystal form such as polymorphism and solvatomorphism may alter physical properties such as solubility and chemical reactivity. ${ }^{5}$ Second, information on decomposition products and synthesis impurities is important, because their presence in the bulk drug may impact crystal growth kinetics, ${ }^{6,7}$ size distribution, and morphology. ${ }^{8}$ Moreover, impurities may exhibit their own biological activities and thus should be controlled in accordance with the regulatory thresholds. ${ }^{9}$

Formulations with TETA. $2 \mathrm{HCl}$ have been studied by Fujito et al. and they have shown that this active pharmaceutical ingredient (API) is sensitive to moisture. ${ }^{10}$ The existence of polymorphs has been reported, ${ }^{11}$ which has recently been confirmed by the publication of two crystal structures (Table 1). ${ }^{12}$ In addition, a dihydrate of TETA. $2 \mathrm{HCl}$ has been described in the literature and its structure has been solved (Table 1). ${ }^{12,13}$ The volumes of the three structures have been reported as a function of temperature. ${ }^{12}$

The melting point of TETA $2 \mathrm{HCl}$ has been reported in the form of a melting range between 115 and $118{ }^{\circ} \mathrm{C}$ in the literature, but it has not been related to the existing polymorphs. ${ }^{14}$ However, a patent discussing the synthesis of several salts of TETA describes both form I and form II and provides two DSC curves with melting temperatures $121.96{ }^{\circ} \mathrm{C}(395.11 \mathrm{~K})$ and $116.16^{\circ} \mathrm{C}(389.31 \mathrm{~K})$ and melting enthalpies of $234.54 \mathrm{~J} \mathrm{~g}^{-1}\left(51.401 \mathrm{~kJ} \mathrm{~mol}^{-1}\right)$ and $203.64 \mathrm{~J} \mathrm{~g}^{-1}\left(44.630 \mathrm{~kJ} \mathrm{~mol}^{-1}\right)$ for forms I and II, respectively. ${ }^{15}$ Form I, with the higher melting point, can therefore be considered the stable form just 
below the melting points, however, it is not known which of the two observed polymorphs is stable at room temperature and under which conditions the dihydrate may form.

Table 1. Crystallographic information on the known crystal structures of TETA.2HCl

\begin{tabular}{|l|l|l|l|l|l|}
\hline Form & $\mathrm{M}\left(\mathrm{g} \mathrm{mol}^{-1}\right)$ & Space group & Volume $\left(\AA^{3}\right)$ & $\mathrm{Z}$ & Ref \\
\hline I & 219.16 & Monoclinic $P 2_{1} / n$ & $572.63(3)$ & 2 & 12 \\
\hline II & 219.16 & Monoclinic $P 2_{1} / c$ & $1167.95(12)$ & 4 & 12 \\
\hline Dihydrate & 255.20 & Monoclinic $P 2_{1}$ & $655.2(2)$ & 4 & 13 \\
\hline
\end{tabular}

Concerning the chemical stability, many analytical detection techniques have been applied to investigate TETA. $2 \mathrm{HCl}$, including conductivimetry, ${ }^{16}$ fluorimetry, ${ }^{17}$ and more recently mass spectrometry coupled to HPLC. ${ }^{18}$ However, these techniques were used to analyze TETA assays in biological fluids and to our knowledge no characterization of the impurities due to degradation has been published yet. Thus, despite the presence of a reasonable body of work on the pharmaceutical implications of TETA and the presence of structural data, very little is known about the chemical and physical stability of TETA.2HCl.

In this paper the chemical and physical stability of TETA.2HCl in the solid state and its solubility will be discussed based on new experimental results on chemical decomposition and phase transition data and on crystallographic information from the literature. ${ }^{12,13,15}$

\section{Materials and Methods}

\subsection{Materials}

TETA.2 $2 \mathrm{HCl}$ (standard substance 99.4\%, $219.16 \mathrm{~g} \mathrm{~mol}^{-1}$ ), analytical grade heptafluorobutyric acid (HFBA for mobile phase preparation), and high-performance-liquid-chromatography (HPLC) grade acetonitrile (ACN) were purchased from Sigma-Aldrich (Steinheim, Germany). Ultrapure water was obtained by deionization and filtration through a Milli-Q water purification system (Millipore, StQuentin-en-Yvelines, France). TETA.2HCl was used as obtained without further purification. Independent stock solutions of $100 \mu \mathrm{gl}^{-1}$ TETA.2 $\mathrm{HCl}$ were prepared by dissolving the appropriate amounts of the substance in ultrapure water.

\subsection{Equipment}

\subsubsection{Differential scanning calorimetry and thermogravimetry}


Differential scanning calorimetry (DSC) experiments were carried out with a PYRIS Diamond DSC thermal analyzer from Perkin Elmer (Waltham, United States). Indium $\left(T_{\text {fus }}=429.75 \mathrm{~K}, \Delta_{\text {fus }} \mathrm{H}=28.45 \mathrm{J.g}\right.$

$\left.{ }^{1}\right)$ was used as a standard for temperature and enthalpy calibration and samples of approximately 5 $\mathrm{mg}$ were analyzed in pierced aluminum pans at various heating rates (from $1 \mathrm{~K} \mathrm{~min}^{-1}$ to $20 \mathrm{~K} \mathrm{~min}^{-1}$ ) under nitrogen atmosphere. Samples were weighed in aluminum pans using a microbalance sensitive to $0.01 \mathrm{mg}$. Pure API samples have been studied as well as mixtures of API with water. Thermogravimetric analysis of pure API samples was carried out using a SDT Q600 system (TA instruments, New Castle, United States).

\subsubsection{High pressure differential thermal analysis}

The transitions observed by DSC have been studied with high-pressure differential thermal analysis (HP-DTA) too. An in-house constructed HP-DTA, similar to the apparatus previously built by Würflinger ${ }^{19}$ with temperature and pressure ranges from 203 to $473 \mathrm{~K}$ and 0 to $300 \mathrm{MPa}$, respectively, was used. Samples were sealed in cylindrical tin pans and to ensure that in-pan volumes were free from residual air, specimens were mixed with an inert perfluorinated liquid (Galden ${ }^{\circ}$ from Bioblock Scientifics, Illkirch, France) before sealing. HP-DTA scans were carried out with a heating rate of $2 \mathrm{~K} \mathrm{~min}^{-1}$. In addition, DSC runs at ordinary pressure (i.e., in standard aluminum pans) with mixtures of TETA $2 \mathrm{HCl}$ and perfluorinated liquid were carried out to verify that the latter was inert.

\subsubsection{Dynamic Vapor Sorption}

Dynamic Vapor Sorption (DVS) was carried out with a DVS-1000 from Surface Measurement Systems (Alperton, United Kingdom). About $10 \mathrm{mg}$ of TETA. $2 \mathrm{HCl}$ has been used in each experiment and the relative humidity was slowly varied in the range from 0 to $90 \%$. The sample was considered stable with respect to the imposed water vapor once the fluctuation of its mass was below 0.0001 $\mathrm{m} \% / \mathrm{min}$.

\subsubsection{Liquid-Chromatography-Mass spectrometry}

Reversed-phase liquid chromatography (LC) coupled with Mass Spectrometry (MS) detection has been used to obtain the impurity profiles of TETA $2 \mathrm{HCl}$.

The LC system (Dionex Corporation, Sunnyvale, United states) consisted of an Ultimate 3000 quaternary pump and an AS-3000 auto sampler. The column was a Waters Polaris C18 (Waters, Milford, United States) with $100 \mathrm{~mm}$ length, $2.1 \mathrm{~mm}$ internal diameter, and $5 \mu \mathrm{m}$ particle size. The flow rate was set at $0.2 \mathrm{~mL} \mathrm{~min}^{-1}$ and the sample injection volume was $20 \mu \mathrm{L}$.

A mobile phase gradient was set up (solvent A: HFBA in ultrapure water $0.1 \%(v / v)$, solvent $B$ : HFBA in ACN $0.1 \%(v / v))$ to ensure absence of impurity co-elution. Table 2 describes the gradient 
distribution during the analysis. Inter-run stabilization was set to 5 minutes. The measurement time was long enough to ensure observation of late eluting impurities.

Mass spectrometry detection consisted of an LCQ 3200-QTRAP quadrupole ion trap mass spectrometer (ABSciex, Framingham, United States) and an electrospray ionization (ESI) source. The ESI source operated in positive ionization mode, with a $5.5 \mathrm{kV}$ spray voltage. The sheath/auxiliary gas was highly pure nitrogen (flow rate: $10 \mathrm{psig}$ ). Capillary voltage was set to $9.0 \mathrm{~V}$ and the capillary temperature was $225^{\circ} \mathrm{C}$. A range from 50 to 800 mass-to-charge ratio was scanned in the detector. LC-MS conditions were optimized in order to ensure detection of the main impurities. A $0.05 \%$ threshold was chosen in accordance with $\mathrm{ICH}$ recommendations ${ }^{20}$ and final concentrations of the samples were at least $50 \mathrm{mg} \mathrm{mL}^{-1}$ in ultrapure water considering the detection limit of the method. Analyst ${ }^{\circ}$ (ABSciex) was used as data acquisition software. Processing of the MS data was carried out with MS Manager software version 12 (ACD Labs, Toronto, Canada). Theoretical fragmentation patterns were computed using MS Fragmentor software version 12 (ACD Labs, Toronto, Canada).

Table 2. Mobile phase gradient for the HPLC experiments

\begin{tabular}{|c|c|c|}
\hline Time after injection (min) & Solvent A (\% v/v) & Solvent B (\% v/v) \\
\hline 0 & 85 & 15 \\
\hline 15 & 70 & 30 \\
\hline 20 & 70 & 30 \\
\hline 21 & 85 & 15 \\
\hline 25 & 85 & 15 \\
\hline
\end{tabular}

\subsection{Physical stability measurements}

The effect of temperature on TETA. $2 \mathrm{HCl}$ was investigated using the SDT and DSC apparatuses. The glass transition and polymorphism were studied by quenching molten samples. The effect of water vapor on solid TETA.2 $\mathrm{HCl}$ was assessed by static and dynamic moisture exposure, using saturated salt solutions and the DVS apparatus. In addition, TETA.2 $\mathrm{HCl}$-water mixtures have been studied by DSC.

\subsection{Chemical stability in solid state - accelerated stability studies}

For the chemical stability study in the solid state, bulk powder samples of approximately $1 \mathrm{~g}$ were exposed to three sets of stress conditions.

(A) exposure to ambient humidity (i.e uncontrolled) at $20{ }^{\circ} \mathrm{C} \pm 2{ }^{\circ} \mathrm{C}$ aimed to simulate a realistic usage condition (monitoring revealed a humidity ranging between 30 and $40 \% \mathrm{RH}$ (heated building in winter)). 
(B) exposure to a relative humidity of $43 \% \mathrm{RH}$ at room temperature $20^{\circ} \mathrm{C} \pm 2{ }^{\circ} \mathrm{C}$.

(C) exposure to a relative humidity of $75 \% \mathrm{RH}$ at a temperature of $40{ }^{\circ} \mathrm{C} \pm 1{ }^{\circ} \mathrm{C}$ (accelerated stress test).

Samples were conditioned in $1 \mathrm{~mL}$ brown glass vials. Chemical purity was assessed at days 0,7 , 26,35 , and 42 . A sample was considered expired by degradation once its TETA content was less than $90 \%(\% \mathrm{~m} / \mathrm{m})$ of a native sample of TETA. $2 \mathrm{HCl}$.

\section{Results and Discussion}

\subsection{Chemical purity of the commercial product}

The chemical purity of triethylenetetramine dihydrochloride was determined by HPLC-MS. The experimental daughter-ion mass spectrum of TETA. $\mathrm{H}^{+}$( $25 \%$ collision-induced dissociation) and the proposed fragmentation pathway are presented in Figure 2. The pathway is a succession of single and multiple cleavages of $\mathrm{C}-\mathrm{N}$ bonds.

By HPLC, the overall purity of the sample was found to be $99.5 \% \mathrm{~m} / \mathrm{m}$. One impurity was present in the commercial sample as can be seen in the chromatogram in the supplementary information (Figure S1). As this impurity was detected in the original material stored under recommended conditions (tightly closed container at room temperature and protected from light), it is most likely due to the synthesis (peak labeled $\mathrm{SI}_{1}$ in Figure $\mathrm{S} 1$ ). $\mathrm{MS} / \mathrm{MS}$ analysis of the $\mathrm{SI}_{1}$ elution peak results in an $\mathrm{m} / \mathrm{z}$ of 104 and it leads to a similar fragmentation as observed for TETA. $\mathrm{H}^{+}\left(\right.$TETA. $\mathrm{H}^{+}(\mathrm{m} / \mathrm{z}$ 147): 70, $87,104,113$, and 130 and for $\mathrm{SI}_{1}$ (m/z 104): 70 and 87), indicating that $\mathrm{SI}_{1}$ is closely related; therefore it is most likely diethylenetriamine, which is a known impurity of TETA.

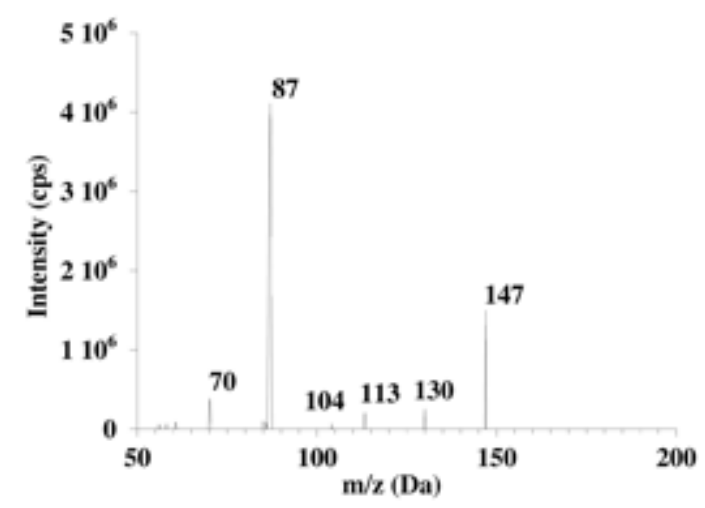

a

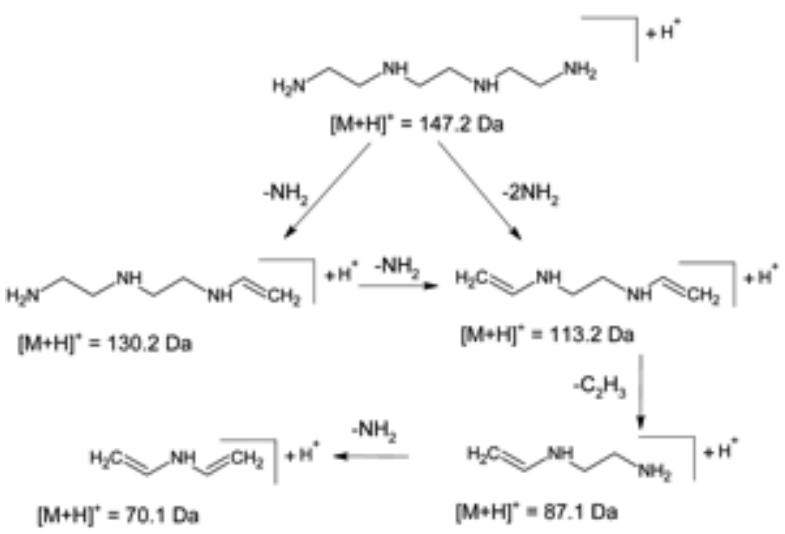

b

Figure 2 (a) MS ${ }^{2}$ scan of TETA (25\% Collision-induced dissociation) (b) proposed fragmentation pathway for TETA. 


\subsection{Stress tests}

TETA. $2 \mathrm{HCl}$ has been subjected to different temperatures and humidities (see section 2.4). In particular for conditions B and C, a marked decrease of the amount of TETA is observed with time (Figure 3). At $40{ }^{\circ} \mathrm{C}$ and $75 \% \mathrm{RH}$ (condition $\mathrm{C}$ ), the $\mathrm{SI}_{1}$ impurity increased and two new impurities appeared: $\mathrm{DI}_{1}$ with $\mathrm{m} / \mathrm{z} 137$ and $\mathrm{DI}_{2}$ with $\mathrm{m} / \mathrm{z} 126$ (Shown in Figure $\mathrm{S} 1$ in the Supporting Information). It demonstrates that TETA. $2 \mathrm{HCl}$ is sensitive to humidity and increased temperature in accordance with previous findings by Fujito et al. ${ }^{10}$

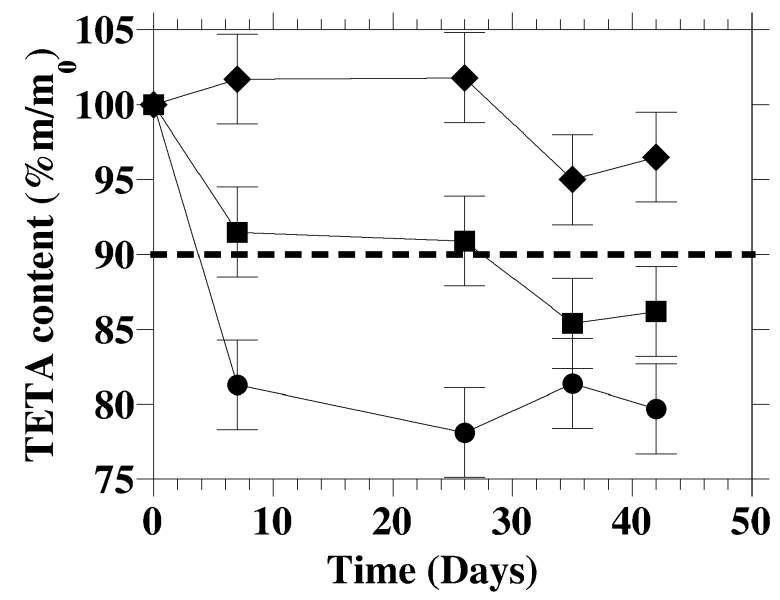

Figure 3. Evolution of the quantity of TETA (\% $\mathrm{m} / \mathrm{m}_{0}$ obtained by HPLC-MS) in samples under elevated temperature and/or humidity (solid diamonds: ambient conditions $\left(20^{\circ} \mathrm{C}\right.$, uncontrolled humidity); solid squares: $20^{\circ} \mathrm{C}, 43 \% \mathrm{RH}$; solid circles: $40^{\circ} \mathrm{C}, 75 \% \mathrm{RH}$, dashed line: lower acceptance limit)

\subsection{Thermal behavior under ordinary conditions}

Ordinary conditions are defined in this paper as a system in equilibrium with its vapor phase. It implies that melting transitions but also solid-solid transitions are observed in equilibrium with their partial vapor pressure. Thus, the obtained transition temperatures are triple point temperatures. It can be assumed that in the small volume of a DSC capsule the partial pressure of a chemical compound will be quickly in equilibrium with its condensed phase. Thus standard DSC measurements provide in general data under ordinary conditions.

The melting point of TETA. $2 \mathrm{HCl}$ was found at $394.6 \pm 1 \mathrm{~K}\left(121.5^{\circ} \mathrm{C}\right)$ with a melting enthalpy of $242 \pm 9 \mathrm{~J} \mathrm{~g}^{-1}\left(53.0 \pm 1.9 \mathrm{~kJ} \mathrm{~mol}^{-1}\right)$. Cooling the melted sample down to $213 \mathrm{~K}$ with $10 \mathrm{~K} \mathrm{~min}^{-1}$ and reheating gave rise to a glass transition at $256.2 \pm 1 \mathrm{~K}\left(-16.9{ }^{\circ} \mathrm{C}\right.$, midpoint) on heating (Figure 4). Subsequently an exothermic peak was observed linked to recrystallization, which occurred generally between $300 \mathrm{~K}$ and $360 \mathrm{~K}$. After recrystallization a melting peak was observed at $387.1 \pm 1 \mathrm{~K}(114.0$ ${ }^{\circ} \mathrm{C}$, Figure 4). The enthalpy associated with this melting transition is $200 \pm 11 \mathrm{~J} \mathrm{~g}^{-1}\left(43.9 \pm 2.4 \mathrm{~kJ} \mathrm{~mol}^{-1}\right)$. 
Melting peaks in a sealed capsule often had a liquidus like appearance that improved by piercing the pan. Generally, no significant weight loss was observed after the DSC measurements with pierced pans. Even though other causes cannot be excluded, it may be due to a small amount of adsorbed water as the compound is fairly hygroscopic and easily forms a hydrate as will be presented below. In TGA measurements and in infrared measurements the presence of small quantities of water was often observed. Degradation of the sample during the melt has been excluded, because the HPLC profiles of the melted samples were virtually the same from those of the commercial sample. However, the melting point and melting enthalpy appeared to decrease slightly after the compound had been stored for several months under the recommended conditions (see 3.1 above), with a clear effect on recrystallization into form II, in particular visible in its melting enthalpy, which may drop to $160 \mathrm{~J} \mathrm{~g}^{-1}$ for samples that have been stored for a long time. Although not confirmed, this may be due to slow or incomplete crystallization of the sample because oxidized functional groups prevent or slow down recrystallization.

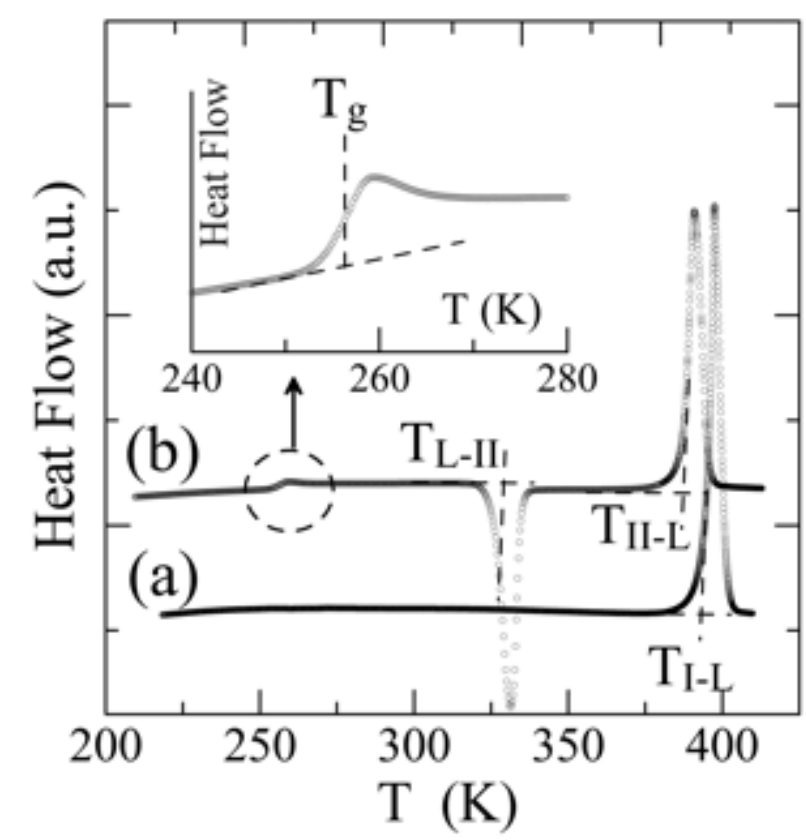

Figure 4. DSC curve $\left(10 \mathrm{~K} \mathrm{~min}^{-1}\right)$ of the commercial form (form I): heating - cooling (not shown) - heating. First heating leads to fusion of form I $\left(T_{1-L}\right)$. Reheating the undercooled liquid gives rise to a glass transition $\left(T_{g}\right)$, recrystallization $\left(T_{L-I I}\right)$ and fusion of a different solid phase (form II, $\left.\mathrm{T}_{\mathrm{II}-\mathrm{L}}\right)$ ).

\subsection{The pressure-temperature phase diagram}

The fusion of TETA. $2 \mathrm{HCl}$ has been studied as a function of pressure and temperature and the results are provided in Figure 5. Both solid - liquid equilibria of form I and form II can be described by a linear equation in the studied pressure and temperature range. The pressure $P$ (in $\mathrm{MPa}$ ) as a function of the temperature $T$ (in $\mathrm{K}$ ) is given by the following two expressions obtained by linear regression: 
Form I - L: $P=-5612(292)+14.2(0.7) T$

Eq. 1

Form II - L: $P=-6489(338)+16.8(0.9) T$

Eq. 2

Using the equilibrium of the highest melting form, useful information can be obtained on the properties of the liquid state. The slope $(\mathrm{d} P / \mathrm{d} T)$ of a phase equilibrium and thus of Eq. 1 is related to the transition enthalpy $(\Delta H)$ and the volume change $(\Delta V)$ on melting as demonstrated by the Clapeyron equation:

$$
\frac{d P}{d T}=\frac{\Delta S}{\Delta V}=\frac{\Delta H}{T \Delta V}
$$

Eq. 3

$\Delta S$ is the transition entropy change and $T$ is the temperature at which the enthalpy change has been determined. With the Clapeyron equation, the specific volume of the liquid can be calculated on melting.

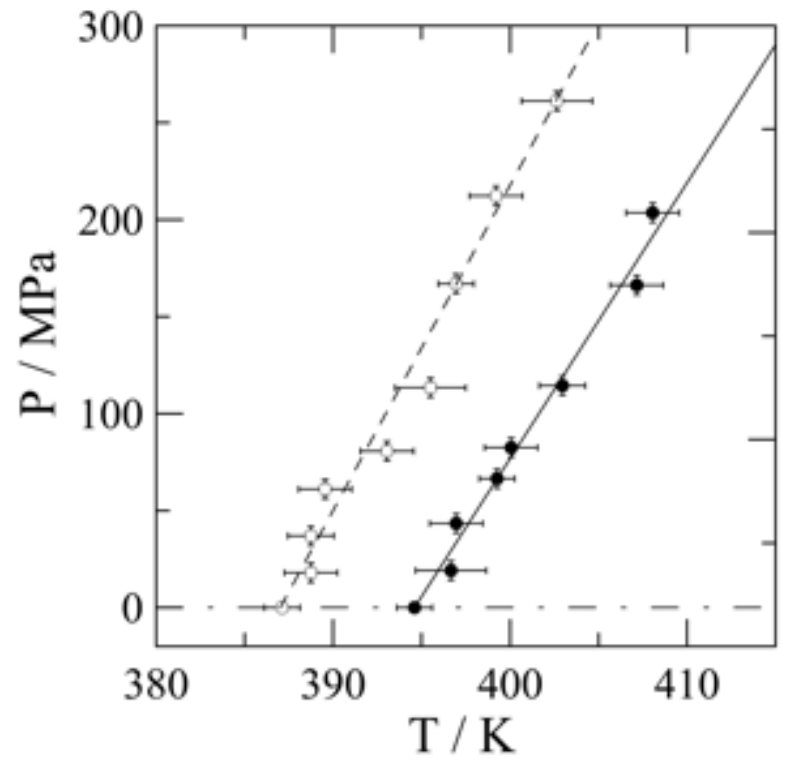

Figure 5 High-Pressure differential thermal analysis data of the fusion of TETA· $2 \mathrm{HCl}$ with straight lines obtained by linear regression, open circles (dashed line): fusion of form II, solid circles (solid line): fusion of form I.

The volumes of the three known crystal structures with TETA $2 \mathrm{HCl}$ have been reported previously as a function of the temperature. ${ }^{12}$ Using $Z$, which can be found in Table 1 , the unit-cell volumes 
reported in the literature can be expressed in the form of specific volumes $\left(\mathrm{cm}^{3} \mathrm{~g}^{-1}\right)$ of the crystals as a function of the temperature $(\mathrm{K})$ :

form I:

$$
v_{1, \text { spec }}=0.7750(2)+4.73(8) \times 10^{-5} T
$$

Eq. 4

form II: $\quad v_{\|, \text {spec }}=0.775(3)+1.06(9) \times 10^{-4} T$

Eq. 5

dihydrate: $\quad v_{2 \mathrm{H} 2 \mathrm{O}, \mathrm{spec}}=0.7548(3)+7.94(12) \times 10^{-5} \mathrm{~T}$

Eq. 6

This information will be used here to obtain an estimate of the density of the liquid state.

Using the slope of Eq. 1, $\mathrm{dP} / \mathrm{d} T=14.2 \mathrm{MPa} \mathrm{K}^{-1}$, the melting temperature of form I, $T=T_{\mathrm{I}-\mathrm{L}}=394.6$ $\mathrm{K}$, and the enthalpy of fusion $\Delta_{1-L} H=242 \mathrm{~J} \mathrm{~g}^{-1}$, the specific volume change on melting becomes $\Delta_{\mathrm{I}-\mathrm{L}} \mathrm{V}=$ $0.0431 \pm 0.0038 \mathrm{~cm}^{3} \mathrm{~g}^{-1}$ with Eq. 3 . Because the volume of form I is known at its melting point through Eq. $4, v_{1, \text { spec }}=0.7937 \mathrm{~cm}^{3} \mathrm{~g}^{-1}$, the specific volume of the liquid at the melting temperature can be calculated and is found to be $v_{\mathrm{L}, \text { spec }}(394.6 \mathrm{~K})=0.8367 \mathrm{~cm}^{3} \mathrm{~g}^{-1}$. The increase in volume on melting is 5.4 \% (or max $5.9 \%$ ), which is rather low considering that most small molecules exhibit a volume increase on melting of about $11 \%{ }^{21-24}$

The maximum thermal expansion of the liquid can be found by linear interpolation between the specific volume of the liquid at the melting point of form I and the specific volume of form II at the glass transition temperature, $T_{\mathrm{g}}=254 \mathrm{~K}$ and $v_{11, \text { spec }}=0.8019 \mathrm{~cm}^{3} \mathrm{~g}^{-1}$, as the glass phase cannot have a specific volume lower than this crystalline phase. It leads to a slope of liquid volume versus temperature of $2.5 \times 10^{-4} \mathrm{~cm}^{3} \mathrm{~g}^{-1} \mathrm{~K}^{-1}$ and it results in the following expression for the thermal expansion of the liquid: $v_{\mathrm{L}}=0.7390+2.5 \times 10^{-4} \mathrm{~T}$ with $v_{\mathrm{L}}(\mathrm{T}=0)=0.7390 \mathrm{~cm}^{3} \mathrm{~g}^{-1}$. The expansion can be compared with that of other molecular pharmaceuticals by using the thermal expansion coefficient $\alpha_{\mathrm{vL}}=$ $(\mathrm{d} v / \mathrm{d} T) / v_{\mathrm{L}}(\mathrm{T}=0)=3.4 \times 10^{-4} \mathrm{~K}^{-1}$. Data on liquids of small molecular pharmaceuticals tend to an average $\alpha_{\mathrm{VL}}$ of about $1.2 \times 10^{-3} \mathrm{~K}^{-1},{ }^{23,24}$ the maximum thermal expansion of liquid TETA. $2 \mathrm{HCl}$ is less than a third of the average value. A similar trend can be seen for the solids. From Eq. 4 and Eq. 5 it can be derived that $\alpha_{\mathrm{vl}}=6.1 \times 10^{-5} \mathrm{~K}^{-1}$ and $\alpha_{\mathrm{v} \mid l}=1.4 \times 10^{-4} \mathrm{~K}^{-1}$ (and for the dihydrate $1.1 \times 10^{-4} \mathrm{~K}^{-1}$ ). This compares against an average value of the solid thermal expansion coefficient for pharmaceuticals of $2.1 \times 10^{-4} \mathrm{~K}^{-}$ ${ }^{1}$; thus the thermal expansion of TETA.2HCl is overall small. 
The two-phase equilibria in Figure 5 involve each the melting of a different solid form and therefore they cannot be both stable. Because fusion is an order - disorder transition there is no significant kinetic barrier and the actual measured melting temperature is the equilibrium temperature between the solid and the liquid. Form I melts at a higher temperature than form II and must be the more stable solid form in the temperature interval between the two melting equilibria and possibly below. According to the rules by Burger and Ramberger, ${ }^{25}$ the system must be monotropic as the higher melting form I has the higher melting enthalpy. Although it may be correct for this system, the "heat of transition rule" and "heat of fusion rule" are only based on the temperature dimension and they do not take into account the effect of pressure. It is well known that melting equilibria under pressure may cross each other and that monotropic systems can become enantiotropic under pressure or vice versa. ${ }^{26,27}$ To determine whether a stable domain for form II exists in the pressure-temperature plane, a $P-T$ phase diagram can be constructed using topological arguments, which are purely based on thermodynamics and not on rules that may possess exceptions. The strength of the topological method is that it is often overdetermined, which allows to verify consistency or when certain data is lacking, such as the density of the melt, which is often difficult to measure, it can be calculated through the topological approach.

It can be seen that the slope of the II - L equilibrium is steeper than the one for I - L. In addition, the ordinate at $\mathrm{T}=0 \mathrm{~K}$ is lower for the $\mathrm{II}-\mathrm{L}$ equilibrium. This indicates that the two equilibria diverge with increasing pressure and that they intersect at negative pressure. Setting expressions Eq. 1 and Eq. 2 equal to each other satisfying the condition of equal pressure at the intersection of the two equilibria, one finds a I-II-L triple point temperature of $345 \mathrm{~K}$ and a pressure of $-710 \mathrm{MPa}$. Because forms I and II are in equilibrium with each other at this triple point, the I-II equilibrium line must cross through this point too.

The slope of the I-II equilibrium can be found using the Clapeyron equation (Eq. 3), once the enthalpy change and the volume change for the I-II transition have been determined. At the I-II-L triple point temperature of $345 \mathrm{~K}$ the specific volumes are $v_{1}=0.7913 \mathrm{~cm}^{3} \mathrm{~g}^{-1}$ and $v_{\|}=0.8115 \mathrm{~cm}^{3} \mathrm{~g}^{-1}$ leading to $\Delta_{I_{\rightarrow} \|} V=0.0202 \mathrm{~cm}^{3} \mathrm{~g}^{-1}$; hence an increase in pressure will stabilize form I, which has the smallest specific volume (Le Chatelier). The entropy difference between the two forms can be obtained from the melting enthalpies: $\Delta_{I_{\rightarrow} \mid l} S=\Delta_{l_{\rightarrow}} H / T_{I_{\rightarrow} L}-\Delta_{\|_{\rightarrow} L} H / T_{\|_{\rightarrow} L}=0.0949 \mathrm{JK}^{-1} \mathrm{~g}^{-1}$ (taking rounding into account). The positive value indicates according to the Le Chatelier principle that an increase in temperature will favor the formation of form II. Using the two inequalities an average slope of 4.7 $\mathrm{MPa} \mathrm{K}^{-1}$ is found for the I-II equilibrium, which is less steep than the two melting equilibria (Eq. 1 and Eq. 2). It implies that the I-II equilibrium only exists in domains where either the vapor phase or the 
liquid are stable and that hence the I-II equilibrium has no stable pressure-temperature interval (Figure 6). Extrapolating the I-II equilibrium line to $0 \mathrm{MPa}$, which is approximately the pressure of the system under atmospheric conditions, one finds a transition temperature of $496 \mathrm{~K}$ (By approximation, this temperature in combination with a pressure of $0 \mathrm{MPa}$ can be considered the triple point I-II-V (Figure 6a)) The I-II transition temperature can be compared to the alternative value of $436 \mathrm{~K}$, obtained with an equation based on the melting temperatures and melting enthalpies of the two forms and neglecting the heat capacities. ${ }^{24,28}$ Both transition temperatures here obtained, $496 \mathrm{~K}$ and $436 \mathrm{~K}$, should be considered estimates.

If the latter temperature is used for the coordinates of the triple point I-II-V (436 K, $0 \mathrm{MPa})$ in combination with the I-II-L triple point coordinates of $345 \mathrm{~K},-710 \mathrm{MPa}$, the I-II equilibrium would have the slope $7.8 \mathrm{MPa} \mathrm{K}^{-1}$. This slope is twice as large as the one found by Clapeyron, but it is still considerably smaller than the slopes of the melting equilibria. Thus the I-II equilibrium has no stable domain in the entire pressure-temperature phase diagram. It implies that form I is the only stable form because TETA.2 $\mathrm{HCl}$ will always melt before it reaches its I-II equilibrium (Figure 6a). Form II has thus an overall monotropic phase relationship with form I and the stable phases of the known pressure-temperature phase diagram are form I, the liquid and the vapor (Figure 6b). Systems with similar overall monotropic phase behavior are biclotymol, ${ }^{29}$ rimonabant, $^{30} \mathrm{FK}_{664}{ }^{24}$ and more recently rotigotine, for which its unexpected monotropy caused a temporary withdrawal from the market. ${ }^{31}$
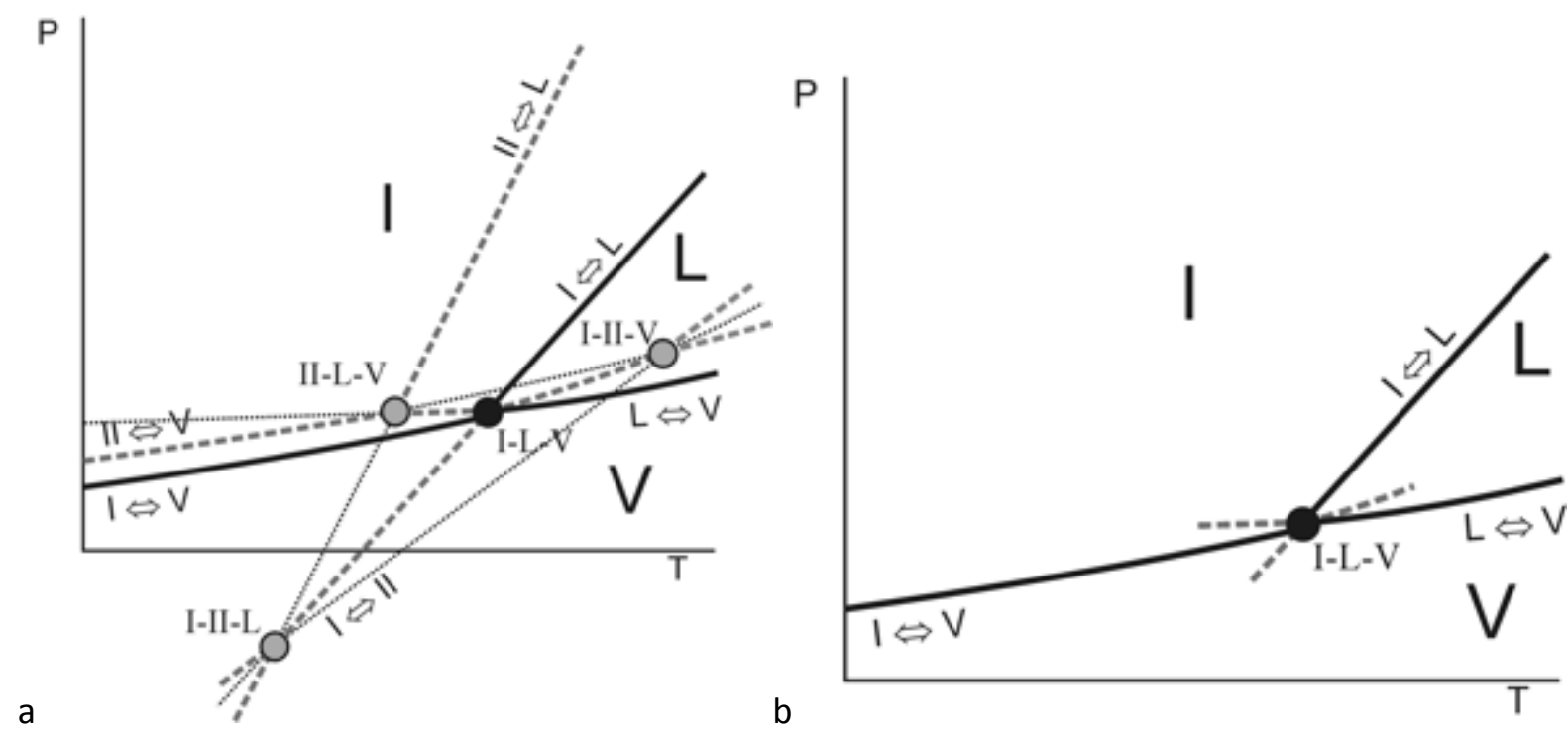

Figure 6. The pressure-temperature phase diagram of pure $T E T A \cdot 2 \mathrm{HCl}$ (a) containing all known phases and phase transitions. Domains: I: stable form I, L: stable liquid, V: stable vapor phase, phase equilibria: black solid lines: stable, grey dashed lines: metastable, black dotted lines: supermetastable, triple points: solid black circle: stable, grey circle: metastable. (b) phase diagram containing only the stable domains, phase equilibria and triple point. The axes are not to 
scale; in particular the pressure axis is expanded at low pressures to demonstrate the stability domains of the condensed phases in relation to the vapor phase. The stable triple point I-L-V is located at T $=394.6 \pm 1 \mathrm{~K}$.

\subsection{The effect of humidity on the stability of TETA $\cdot 2 \mathrm{HCl}$}

To study the phase relationship between pure TETA. $2 \mathrm{HCl}$ and its dihydrate, DVS measurements have been carried out at 20,35 , and $45^{\circ} \mathrm{C}$. It can be seen in Figure 7 that at $20^{\circ} \mathrm{C}$ up to $40 \% \mathrm{RH}$ the water content in the TETA. $2 \mathrm{HCl}$ sample increases gradually, indicative of water adsorption on the surface. At $40 \% \mathrm{RH}$ the water content of the sample jumps to $67 \%$, where the mass remains level indicating that a dihydrate has formed. It can be seen that the higher the temperature, the lower the necessary relative humidity (RH\%) to form the dihydrate. In terms of the partial water vapor pressure, however, it has to be realized that the water vapor quantity that can be dissolved in air is higher at higher temperatures; thus, on an absolute scale a higher partial pressure is needed at increased temperatures to form the dihydrate. In other words, the dihydrate is less stable at higher temperatures as it becomes more prone to evaporation of its water content.

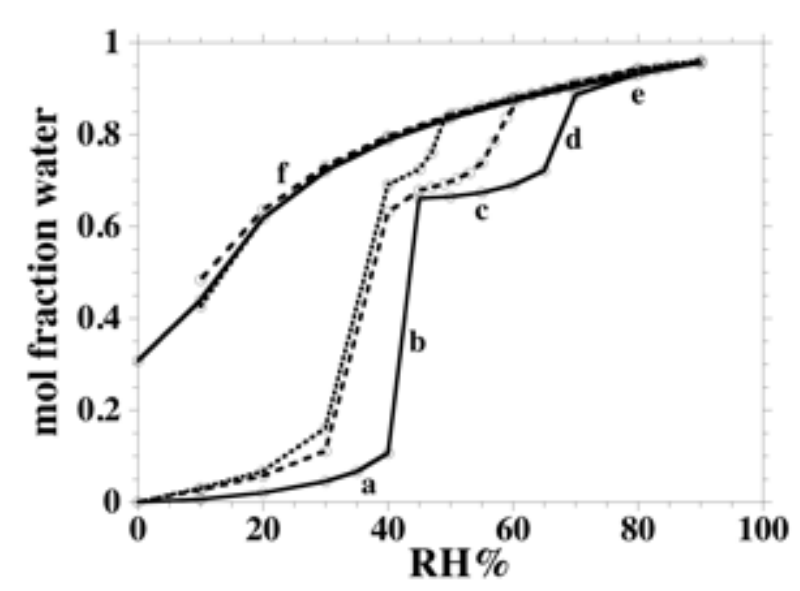

a

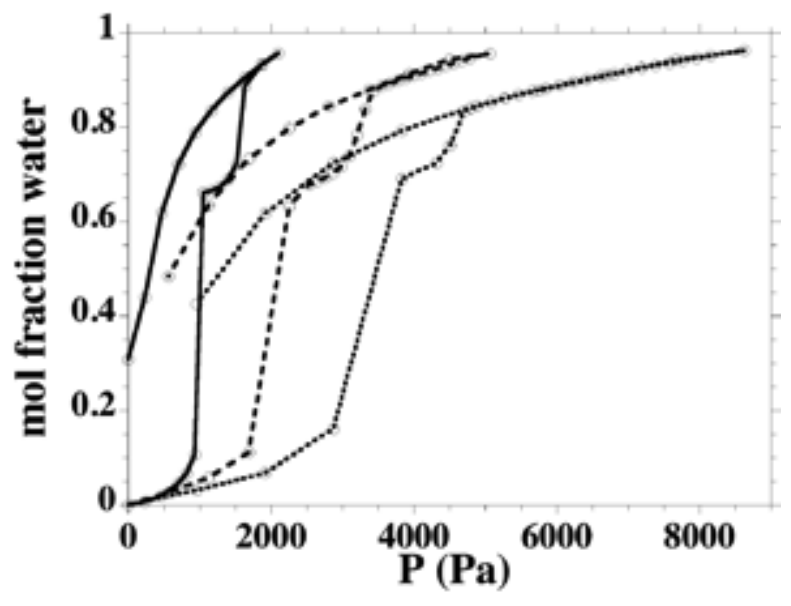

b

Figure 7. DVS data of TETA. $2 \mathrm{HCl}$ at $20^{\circ} \mathrm{C}$ (solid line), $35^{\circ} \mathrm{C}$ broken line, and $45^{\circ} \mathrm{C}$ (dotted line) expressed as the mole fraction of water in the sample as a function of relative humidity (left-hand side) and as a function of partial water vapor pressure in air (right-hand side). The latter is obtained by multiplying the relative humidity fraction with the saturating vapor pressure of water for the given temperatures. Both the responses of the system to water vapor increase and to water vapor decrease are shown. On increasing the humidity, a stepwise increase in water content is observed: domain ' $a$ ' is water adsorption to TETA. $2 \mathrm{HCl}$, ' $b$ ' formation of dihydrate, 'c' water adsorption to the dihydrate, 'd' dissolution of the dihydrate, and ' $e$ ' dilution of the solution. On decreasing the humidity, ' $f$ ' the solution becomes ever more concentrated. In none of the curves shown here, the weight comes back to zero, but this will eventually happen, if the compound is exposed to $0 \%$ humidity for a long enough time (see also Figure S2 in the Supporting Information). For more information on the interpretation of DVS measurements, one can refer to the case of citric acid and its hydrate. ${ }^{32}$

The DVS data provide TETA - water concentrations in equilibrium with the water vapor pressure. Thus the partial vapor pressure and the concentration for specific events can be extracted from the 
measurements as a function of temperature. In the first place the equilibrium pressure of the formation of the dihydrate can be obtained, because it is equal to the pressure at which the sudden water increase levels off (intersection of domains $b$ and $c$ in Figure 7a). The equilibrium pressure of the dihydrate versus temperature can be found in Table 3. After the dihydrate has formed (domain c in Figure 7a), the weight of the sample slowly increases, after which dissolution takes place (domain d). This process stops once the entire dihydrate has dissolved and from then on an increasing vapor pressure dilutes the saturated solution (domain e). Thus, at the intersection of the dissolution and dilution curves ( $d$ and e), the concentration and partial water vapor pressure of the saturated solution can be found. The values have been reported in Table 3. A similar graph as in Figure 7a, but only for the formation of the dihydrate and the hysteresis (persistence of the dihydrate) on reducing the relative humidity can be found in the Supporting Information Figure S2.

Table 3. Partial water vapor pressures $\left(P_{\text {water }}\right)$ at the completion of the formation of the dihydrate and at the point of saturation for TETA. $2 \mathrm{HCl}$ together with the concentration of the saturated solution as a function of the temperature $(T)$

\begin{tabular}{|l|l|l|l|}
\hline$T\left({ }^{\circ} \mathrm{C}\right)$ & 20 & 35 & 45 \\
\hline & \multicolumn{2}{|l|}{ Hydrate formation } \\
\hline$P_{\text {water }}(\mathrm{Pa})$ & 1051 & 2531 & 3834 \\
\hline & \multicolumn{2}{|l|}{} \\
\hline$P_{\text {water }}(\mathrm{Pa})$ & 1645 & 3406 & 4706 \\
\hline Mole fraction TETA.2HCl & 0.10 & 0.12 & 0.16 \\
\hline
\end{tabular}

The $P_{\text {water }}$ values in Table 3 have been plotted as a function of the temperature $T$ in Figure 8 . How the expressions for the lines have been obtained will be explained below in a later section. At this point, the graph in Figure 8 demonstrates which of the phases, solid TETA.2HCl, the dihydrate TETA $2 \mathrm{HCl} \cdot 2 \mathrm{H}_{2} \mathrm{O}$ (narrow area between the dashed line and the solid line), and the solution (= a solution of TETA. $2 \mathrm{HCl}$ in water), is stable depending on the partial water vapor pressure and on the temperature. It is clear that there is always water vapor in the presence of the condensed phases (except for pure TETA.2HCl in a sealed container, which is represented by the $x$-axis).

Considering the experimental conditions for the chemical stability studies discussed above, condition A with about $30 \% \mathrm{RH}$ at $20^{\circ} \mathrm{C}$ can now be located in domain a in Figure 7 a or below the solid line in Figure 8. This confirms the stability of the sample from a physical and chemical point of view; TETA.2HCl (s) is the stable form under these conditions, which gives water little chance to affect it chemically. When at $20^{\circ} \mathrm{C}$, the relative humidity is increased to $43 \%$, TETA.2 $\mathrm{HCl}$ degrades steadily. From Figure 7, it can be seen that under these conditions the dihydrate is the stable form 
and water will therefore be present throughout the crystal. This clearly increases the chemical degradation of the API. Increasing the relative humidity to $75 \%$ and $40^{\circ} \mathrm{C}$ brings the sample into the region where it will liquefy as can be judged from Figure 7. In Figure 8 it will have passed (at $313 \mathrm{~K}$ ) above the dashed line. Clearly, being in solution increases the chances of degradation of the API considerably.

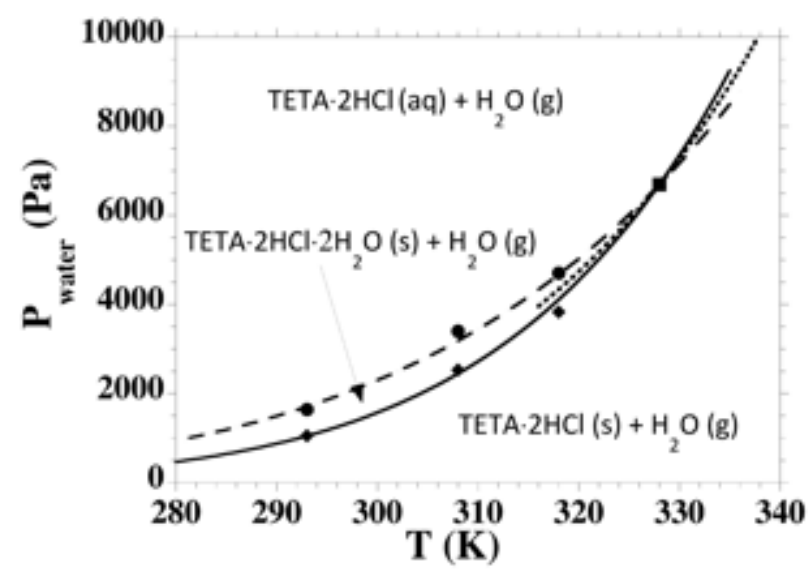

Figure 8. Vapor pressure equilibria as a function of the partial water vapor pressure and the temperature. Solid diamonds: measurement points of the formation of the dihydrate, solid circles: measurement points of the formation of the saturated solution (see Table 3), solid line: fit to the dihydrate formation data (Eq. 8), broken line: fit to the saturated solution data (Eq. 9), dotted line: calculated equilibrium between pure solid TETA.2HCl and its saturated solution (Eq. 13), which becomes

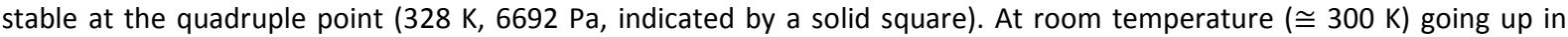
partial water vapor pressure first TETA. $2 \mathrm{HCl}(s)$ is stable, after crossing the solid line TETA. $2 \mathrm{HCl} \cdot 2 \mathrm{H}_{2} \mathrm{O}(\mathrm{s})$ is stable, and crossing the broken line the (saturated) solution becomes stable. Above $328 \mathrm{~K}$, at low water vapor pressure TETA.2HCl (s) is stable and passing the dotted line, the solution becomes stable.

\subsection{The solubility of the different TETA $2 \mathrm{HCl}$ solid forms as a function of temperature}

By increasing the temperature for a mixture of TETA.2HCl with water for a fixed partial water vapor pressure (e.g. $2000 \mathrm{~Pa}$ ), the solid line in Figure 8 will be crossed towards the right-hand side, implying that pure solid TETA. $2 \mathrm{HCl}$ becomes stable in the presence of water vapor. This is illustrated by X-ray diffraction measurements on the dihydrate while increasing the temperature (see the Supporting Information Figure S3 for the diffraction patterns). In Figure 9, the intensity ratio of the dihydrate has been plotted against the form that appears upon dehydration, which is form I. It can be seen that for about four hours the hydrate remained stable. This was the time taken to heat up the sample from $293 \mathrm{~K}$ to $323 \mathrm{~K}$. At $323 \mathrm{~K}$ dehydration started and it took another 4 to 5 hours to obtain pure form I. The amount of dihydrate that disappears is directly proportional to the amount of form I appearing. The dehydration is therefore displacive and this is a clear indication that the structures of 
the dihydrate and form I are related. In addition, thermogravimetric measurements on the dihydrate demonstrate the loss of water and the subsequent melting of form I without any significant thermal event in between (see Supporting Information Figure S4), again indicative of a displacive transition of the dihydrate into form ${ }^{1.33}$ Such dehydration behavior has also been observed previously for potassium guaiacol sulfonate, even though its temperature of dehydration was much higher due to the presence of potassium. ${ }^{34}$

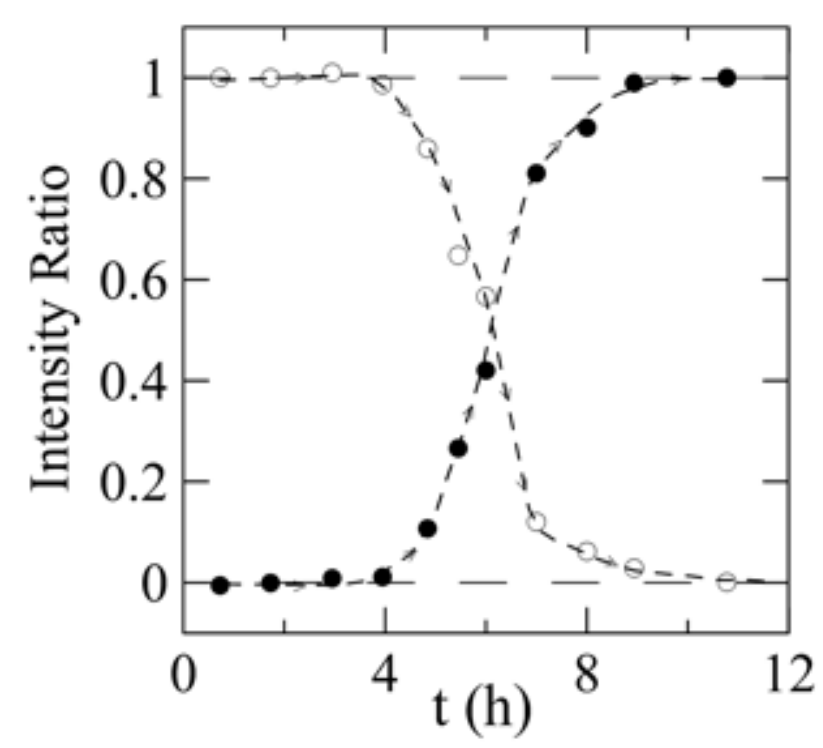

Figure 9. Normalized X-ray intensity (of all peaks together) for the dihydrate (open circles) at $323 \mathrm{~K}$ (first four hours heating from $298-323 \mathrm{~K}$ ) as a function of time. While the dihydrate disappears form I (solid circles) appears and the crossover of the intensities occurs at $50 \%$. This indicates that the transition is displacive as seen before for potassium guaiacol sulfonate. ${ }^{34}$

As it is form I that is in equilibrium with the dihydrate, this information can be used to construct the $T-x$ phase diagram involving TETA $2 \mathrm{HCl}$ form I and water.

DSC measurements have been carried out with different concentrations of water and TETA.2HCl; the curves have been presented in Figure S5 in the Supporting Information. The concentrations and the observed transition temperatures (eutectic, liquidus of the dihydrate, peritectic, and liquidus of form I) have been compiled in Table S1 (supporting information). The three data points on the dihydrate liquidus line obtained by DVS (see Table 3) have been used in the fit too. A description of the calculations to fit the phase diagram has been provided in the supporting materials. The excess parameters have been described by a Redlich-Kister equation and the dihydrate has been described by an expression proposed by Kuznetsov et al. ${ }^{35,36}$ 
It can be observed in Figure 10 that the dihydrate forms a peritectic equilibrium with the liquid phase and form I at $328 \mathrm{~K}$ with a calculated mole fraction of 0.266 for the mole fraction of the liquid. The metastable extension of the dihydrate liquidus line reaches its highest point at its melting temperature (obtained by the fit: $330 \mathrm{~K}$ ). It can be seen that the liquidus values obtained by DVS (mole fractions of saturated solution indicated by triangles) coincide very well with the data obtained by DSC. This demonstrates that the solid-liquid transitions observed in the DSC pans clearly occur in the presence of water vapor and that the actual equilibrium involves a solid, a liquid and a vapor phase.

Below the eutectic temperature $(254.7 \mathrm{~K}$ i.e. about 18 degrees below the melting point of pure water) the liquidus lines become metastable and the two stable phases are ice and dihydrate (solids) at the left-hand side of the diagram. The eutectic concentration, 0.071 mole fraction, has been obtained by the fit. TETA. $2 \mathrm{HCl}$ is in terms of weight fraction extremely soluble in water. However, the formation of the dihydrate reduces the solubility roughly twofold. This can be judged from the extrapolation of the liquidus line of form I from the peritectic temperature (the extension is a dashed line).

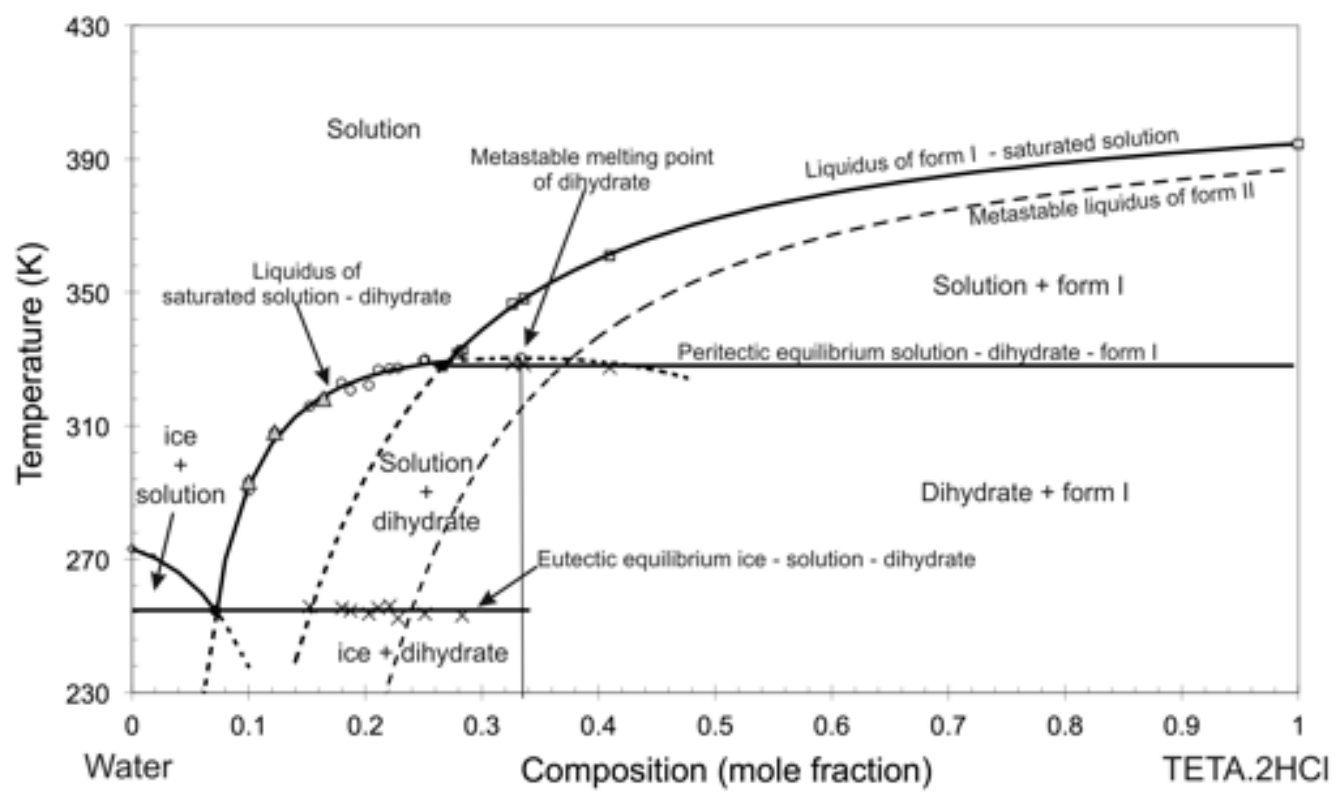

Figure 10. The solubilities of the different forms of TETA.2 $\mathrm{HCl}$ in water (temperature - composition phase diagram). The solid lines are the stable phase transitions and the metastable extensions are indicated by dashed lines. The diagram has been obtained by measurement and fitted using a Redlich-Kister expression for the excess functions. Details of the calculations can be found in the Supporting Information. The coordinates of the eutectic point of water and the dihydrate are 0.071 mole fraction and $254.7 \mathrm{~K}$ and the temperature for the peritectic equilibrium is $328.1 \mathrm{~K}$ with the saturated solution possessing a concentration of 0.266 mole fraction. The metastable melting point of the dihydrate according to the fit is $330 \mathrm{~K}$. Data points for the liquidus of form I: open squares, data points for the liquidus of the dihydrate: open circles, 
data points obtained by DVS: triangles, observed eutectic and peritectic transitions: crosses. Dashed line: estimated solubility of form II (metastable liquidus) using the excess quantities of the liquid and the melting data of form II (Supporting Information).

Form II represents a different phase of form of TETA. $2 \mathrm{HCl}$. This implies that the liquid phase should exhibit the same excess behavior, whereas the difference in Gibbs energy by the solid form II is accounted for by its melting point and melting enthalpy. Because, form II is overall monotropic in relation to form I, its liquidus line will be located below the liquidus line for form I for the entire concentration range of the phase diagram. Its solubility will be consistently higher than that of form I.

Measurements in the DVS demonstrated that the adsorption of water by form II was irregular (not shown), which can probably be interpreted as a transformation of form II into form I or into the dihydrate while dissolving in the presence of water vapor. This is most likely due to increased mobility of the molecules in the presence of water in combination with the fact that either form I or the dihydrate is the stable form instead of form II.

\subsection{The $P_{\text {water }}(T)$ curves and their relation to the T-x phase diagram}

Using information from the $T-x$ phase diagram and the data obtained from the DVS, the relationships of the stabilities of the different condensed phases of TETA. $2 \mathrm{HCl}$ with the partial water vapor pressure and with the temperature can be determined i.e. the lines in Figure 8 can be defined. The equilibrium represented by the solid line in Figure 8 can be represented in the following way:

$$
2 \mathrm{H}_{2} \mathrm{O}(\mathrm{g})+\mathrm{TETA} \cdot 2 \mathrm{HCl}(\mathrm{s}) \rightleftarrows \mathrm{TETA} \cdot 2 \mathrm{HCl}(s) \cdot 2 \mathrm{H}_{2} \mathrm{O}(\mathrm{s})
$$

Eq. 7

The water vapor provided in the DVS experiment, once at the appropriate vapor pressure, will form together with TETA. $2 \mathrm{HCl}$ the dihydrate. At the side of the dihydrate in Eq. 8 water vapor is present too, even if it doesn't appear in the equation, otherwise the dihydrate would not be stable. The equilibrium Eq. 7 also occurs in the lower right-hand side of the $T-x$ phase diagram, where both TETA. $2 \mathrm{HCl}(\mathrm{s})$ and TETA. $2 \mathrm{HCl} \cdot 2 \mathrm{H} 2 \mathrm{O}(\mathrm{s})$ exist in the presence, necessarily, of water vapor, even if it is not indicated (or presumed negligible) in the T-x representation.

The dashed line in Figure 8 represents the equilibrium:

$$
x \mathrm{H}_{2} \mathrm{O}(\mathrm{g})+\mathrm{TETA} \cdot 2 \mathrm{HCl} \cdot 2 \mathrm{H}_{2} \mathrm{O}(\mathrm{s}) \rightleftarrows \mathrm{TETA} \cdot 2 \mathrm{HCl}(\mathrm{l})+(\mathrm{x}+2) \mathrm{H}_{2} \mathrm{O}(\mathrm{l})
$$

Eq. 8 
The dihydrate dissolves into liquid water that is provided as water vapor and a single liquid phase forms that consists of dissolved TETA.2HCl and water. The equilibrium contains $x \mathrm{H}_{2} \mathrm{O}(\mathrm{g})$ molecules, because the concentration of the saturated solution depends on the temperature. The actual concentrations have been reported in Table 3. The same equilibrium can be found in the $T-x$ phase diagram as the liquidus of the dihydrate as this liquidus will only exist in the presence of the water vapor.

The last equilibrium in Figure 8 is the dotted line, which has not been observed experimentally in the DVS, but which must exist, as it is the direct solubilization of TETA. $2 \mathrm{HCl}$ in water without passing through the hydrate:

$$
\mathrm{yH}_{2} \mathrm{O}(\mathrm{g})+\mathrm{TETA} \cdot 2 \mathrm{HCl}(s) \rightleftarrows \text { TETA } 2 \mathrm{HCl}(\mathrm{l})+y \mathrm{H}_{2} \mathrm{O}(\mathrm{l})
$$

Eq. 9

It is also present in the $T-x$ diagram as the liquidus of form I. Clearly, the latter equilibrium only becomes stable, once the dihydrate ceases to be stable. The exchange occurs at the "quadruple point" in Figure 8, where considering the intersecting equilibria, water vapor, solid TETA. $2 \mathrm{HCl}$ (form I), solid TETA $2 \mathrm{HCl} \cdot 2 \mathrm{H}_{2} \mathrm{O}$ and the liquid mixture are in equilibrium. This quadruple point or invariant can be found back in the $T-x$ diagram of Figure 10 as the peritectic equilibrium between the pure solid, the liquid and the dihydrate under the implied presence of the water vapor. Therefore, the crossing of the lines in Figure 7 must occur at $328 \mathrm{~K}$, the peritectic temperature. Another example for which it has been clearly illustrated that the peritectic transition is a quadruple point is citric acid. ${ }^{32}$

The Clausius-Clapeyron equation describes the pressure of a condensed phase as a function of temperature:

$$
\ln (P)=-\frac{\Delta_{\alpha \rightarrow \text { kep }} H}{R T}+B_{\alpha \rightarrow \text { เep }}
$$

Eq. 10 
With $P$ the vapor pressure, $\alpha$ a condensed phase, $\Delta_{\alpha \rightarrow \text { vap }} H$ the enthalpy of vaporization, $R$ the gas constant $8.3145 \mathrm{~J} \mathrm{~K}^{-1} \mathrm{~mol}^{-1}, T$ the temperature and $B_{\alpha_{\rightarrow} \text { vap }}$ an integration constant for the condensed phase $\alpha$. The Clausius-Clapeyron equation is in fact the result of the integration of the Clapeyron equation for a condensed phase - vapor system in which the volume of the condensed phase has been neglected.

In Table 3, the water vapor pressures of two condensed phases, the dihydrate and the saturated solution, have been provided as a function of temperature. Fitting both by plotting $\ln (P)$ against $1 / T$ taking into account the fact that both lines need to cross at $328 \mathrm{~K}$ leads to the two following expressions:

Dihydrate: $\ln \left(P_{\text {water of dihydrate }}\right)=-\frac{42395}{R T}+24.3$

Eq. 11

Saturated solution: $\ln \left(P_{\text {water of sat solution }}\right)=-\frac{31263}{R T}+20.2$

Eq. 12

The enthalpies are given in $\mathrm{mol}^{-1}$ of water and the water vapor pressures in Pa because it is the water that moves between the condensed phase and the vapor phase (the vapor pressure of the salt TETA $2 \mathrm{HCl}$ is considered to be negligible).

The water vapor pressure as a function of temperature for the equilibrium between form I and the liquid (Eq. 9) can be calculated with the temperature of the peritectic equilibrium $T_{\text {quadruple }}$ and

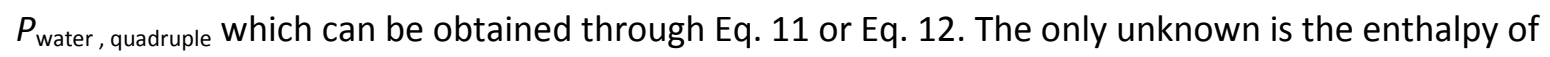
vaporization when water in the saturated solution vaporizes to form pure solid TETA. $2 \mathrm{HCl}$. However, the enthalpy is a function of state and thus cycling around the quadruple point (Figure 8) starting at pure TETA. $2 \mathrm{HCl}(\mathrm{s})$ in the presence of water vapor, passing the dihydrate and the saturated solution 
and returning through the last equilibrium back to the pure solid, the enthalpy difference must be equal to zero. The enthalpy is calculated in the supporting information. The resulting equation for the vapor pressure of the saturated solution against the pure solid is:

Form I saturated solution: $\ln \left(P_{\text {water of form I sat. solution }}\right)=-\frac{39331}{R T}+23.2$

Eq. 13

The line representing this expression runs in between the two other lines in Figure 8 and it is the stable equilibrium above the quadruple point $328 \mathrm{~K}$ and $6692 \mathrm{~Pa}$. It is the partial water vapor pressure belonging to the liquidus line of Eq. 9, the equilibrium between form I and the liquid phase.

\section{Conclusions}

The present paper establishes the interplay between the variables temperature and humidity and the solid phases of triethylenetetramine dihydrochloride. At room temperature, Form I is the stable phase under low relative humidity values and the single stable phase for the pure API, but once above $40 \% \mathrm{RH}$ at $20^{\circ} \mathrm{C}$, the dihydrate of TETA. $2 \mathrm{HCl}$ becomes the stable solid. If the relative humidity rises above $70 \%$, the solid turns into a solution and no solid phase is stable anymore. This physical behavior has been linked directly to the chemical stability of the API; dihydrate degrades more quickly than form I, which is rather stable in the absence of humidity and oxygen, and in the solution the degradation of TETA. $2 \mathrm{HCl}$ accelerates even more.

The role of the water vapor pressure has been demonstrated by the dynamic vapor sorption experiments, but also by the fact that the data obtained by DSC for the water - API mixtures coincides with those obtained by DVS. The vapor phase cannot be ignored in the DSC measurements and must be part of the equilibria in the DVS as well as in the DSC capsules.

X-ray diffraction measurements as a function of the temperature demonstrate the transition of the dihydrate into form I. This implies that there is an equilibrium between the two solids, which 
translates into the peritectic transition in the T-x phase diagram. There is no direct connection between the less stable form II and the dihydrate. DVS measurements of form II do not lead to consistent results, which in turn implies that form II randomly turns into the different phases form I, the dihydrate, or the solution depending on the microstates and conditions in the sample. This random behavior is fully consistent with the lower stability of form II in relation to the other phases.

\section{Acknowledgement}

This work has been supported by the Spanish Ministry of Science and Innovation (grants FIS201454734-P) and the Catalan Government (grant 2014 SGR-581). We thank R. Céolin (University Paris Descartes) for valuable discussion.

\section{References}

1. Ferenci, P.; Czlonkowska, A.; Stremmel, W.; Houwen, R.; Rosenberg, W.; Schilsky, M. EASL Clinical Practice Guidelines: Wilson's Disease. J. Hepatol. 2012, 56, (3), 671-685.

2. Cooper, G. J. S. Selective divalent copper chelation for the treatment of diabetes mellitus. Curr. Med. Chem. 2012, 19, (17), 2828-2860.

3. Cooper, G. J. S. Therapeutic potential of copper chelation with triethylenetetramine in managing diabetes mellitus and alzheimer's disease. Drugs 2011, 71, (10), 1281-1320.

4. Liu, J. H.; Guo, L. X.; Yin, F.; Zheng, X. X.; Chen, G.; Wang, Y. Characterization and antitumor activity of triethylene tetramine, a novel telomerase inhibitor. Biomed Pharmacother 2008, 62, (7), 480-485.

5. Brittain, H. G.; Grant, D. J. R.; Myrdal, P. B., Effects of polymorphism and solid-state solvation on solubility and dissolution rate. In Polymorphism in Pharmaceutical Solids, Brittain, H. G., Ed. Informa Healthcare USA: New York, 2009.

6. Sangwal, K. Kinetic effects of impurities on the growth of single crystals from solutions. J. Cryst. Growth 1999, 203, (1-2), 197-212.

7. Ottens, M.; Lebreton, B.; Zomerdijk, M.; Rijkers, M. P. W. M.; Bruinsma, O. S. L.; Van der Wielen, L. A. M. Impurity effects on the crystallization kinetics of ampicillin. Ind. Eng. Chem. Res. 2004, 43, (24), 7932-7938.

8. Fiebig, A.; Jones, M. J.; Ulrich, J. Predicting the effect of impurity adsorption on crystal morphology. Cryst Growth Des 2007, 7, (9), 1623-1627.

9. ICH-Q3A(R2), Impurities in new drug substances; ICH: 25 October 2006, 2006.

10. Fujito, H.; Tasaki, M.; Mori, M.; Takata, K. A study of efficient preparation of triethylenetetramine dihydrochloride for the treatment of wilsons disease and hygroscopy of its capsule. Yakuzaigaku 1990, 50, (4), 402-408.

11. Jonas, M.; Vaulont, I.; Soi, A.; Schmidt, G. Synthesis of Triethylenetetramines. US Patent 8067641, 2011. 
12. Henriet, T.; Nicolaï, B.; Ghaddar, C.; Barrio, M.; Do, B.; Yagoubi, N.; Tamarit, J.-L.; Rietveld, I. B. Triethylenetetramine dihydrochloride: Interactions and Conformations in two Anhydrous Structures and a Hydrate. Cryst Growth Des 2015, 15, (1), 348-357.

13. Ilioudis, C. A.; Hancock, K. S. B.; Georganopoulou, D. G.; Steed, J. W. Insights into supramolecular design from analysis of halide coordination geometry in a protonated polyamine matrix. New J. Chem. 2000, 24, (10), 787-798.

14. In Drugs: Synonyms and Properties, 2nd edition ed.; Milne, G. W. A., Ed. Ashgate Publising Limited: Hampshire, England, 2002.

15. Jonas, M.; Vaulont, I.; Soi, A.; Schmidt, G. Synthesis of Triethylenetetramines. US Patent 7582796, 2006.

16. Hansen, E. B.; Rushing, L. G.; Thompson, H. C. Determination of Triethylenetetramine Dihydrochloride in Aqueous-Solution by Reversed-Phase Ion-Pairing High-Performance LiquidChromatography and Conductivity Detection. J. Anal. Toxicol. 1985, 9, (4), 167-171.

17. Nakano, Y.; Nohta, H.; Yoshida, H.; Saita, T.; Fujito, H.; Mori, M.; Yamaguchi, M. Liquid chromatographic determination of triethylenetetramine in human and rabbit sera based on intramolecular excimer-forming fluorescence derivatization. J Chromatogr B 2002, 774, (2), 165-172. 18. Lu, J.; Chan, Y. K.; Poppitt, S. D.; Cooper, G. J. S. Determination of triethylenetetramine (TETA) and its metabolites in human plasma and urine by liquid chromatography-mass spectrometry (LC-MS). J Chromatogr B 2007, 859, (1), 62-68.

19. Würflinger, A. Differential thermal-analysis under high-pressure IV. Low-temperature DTA of solid-solid and solid-liquid transitions of several hydrocarbons up to 3 kbar. Ber. Bunsen-Ges. Phys. Chem. 1975, 79, (12), 1195-1201.

20. ICHQ6A: Specifications: Test Procedure and Acceptance Criteria for New Drug Substances and New Drug Products : Chemical Substances, Guidelines; ICH: October 6, 1999, 1999.

21. Goodman, B. T.; Wilding, W. V.; Oscarson, J. L.; Rowley, R. L. A note on the relationship between organic solid density and liquid density at the triple point. J. Chem. Eng. Data 2004, 49, (6), 1512-1514.

22. Céolin, R.; Rietveld, I. B. Phenomenology of polymorphism and topological pressuretemperature diagrams. J. Therm. Anal. Calorim. 2010, 102, (1), 357-360.

23. Céolin, R.; Rietveld, I. B. The topological pressure-temperature phase diagram of ritonavir, an extraordinary case of crystalline dimorphism. Ann. Pharm. Fr. 2015, 73, (1), 22-30.

24. Rietveld, I. B.; Céolin, R. Phenomenology of crystalline polymorphism: overal monotropic behavior of the cardiotonic agent FK664 forms A and B. J. Therm. Anal. Calorim. 2015, 120, (2), 10791087.

25. Burger, A.; Ramberger, R. Polymorphism of Pharmaceuticals and Other Molecular-Crystals .1. Theory of Thermodynamic Rules. Mikrochim. Acta 1979, 2, (3-4), 259-271.

26. Bakhuis Roozeboom, H. W., Die heterogenen Gleichgewichte vom Standpunkte der Phasenlehre. Erstes Heft: Die Phasenlehre - Systeme aus einer Komponente. Friedrich Vieweg und Sohn: Braunschweig, 1901; Vol. 1.

27. Céolin, R.; Rietveld, I. B. X-ray crystallography, an essential tool for the determination of thermodynamic relationships between crystalline polymorphs. Ann. Pharm. Fr. 2016.

28. Yu, L. Inferring Thermodynamic Stability Relationship of Polymorphs from Melting Data. J. Pharm. Sci. 1995, 84, (8), 966-974.

29. Céolin, R.; Tamarit, J. L.; Barrio, M.; Lopez, D. O.; Nicolaï, B.; Veglio, N.; Perrin, M. A.; Espeau, P. Overall monotropic behavior of a metastable phase of biclotymol, 2,2'-methylenebis(4-chloro-3methyl-isopropylphenol), inferred from experimental and topological construction of the related P-T state diagram. J. Pharm. Sci. 2008, 97, (9), 3927-3941.

30. Perrin, M.-A.; Bauer, M.; Barrio, M.; Tamarit, J.-L.; Céolin, R.; Rietveld, I. B. Rimonabant dimorphism and its pressure-temperature phase diagram: A delicate case of overall monotropic behavior. J. Pharm. Sci. 2013, 102, (7), 2311-2321.

31. Rietveld, I. B.; Céolin, R. Rotigotine: unexpected polymorphism with predictable overall monotropic behavior. J. Pharm. Sci. 2015, in press http://dx.doi.org/10.1002/jps.24626. 
32. Lafontaine, A.; Sanselme, M.; Cartigny, Y.; Cardinael, P.; Coquerel, G. Characterization of the transition between monohydrate and the anhydrous citric acid. J. Therm. Anal. Calorim. 2013, 112, 307-315.

33. Petit, S.; Coquerel, G. Mechanism of several solid-solid transformations between dihydrated and anhydrous copper(II) 8-hydroxyquinolinates. Proposition for a unified model for the dehydration of molecular crystals. Chem. Mater. 1996, 8, (9), 2247-2258.

34. Mahé, N.; Nicolaï, B.; Barrio, M.; Perrin, M.-A.; Do, B.; Tamarit, J.-L.; Céolin, R.; Rietveld, I. B. Solid-State Properties and Dehydration Behavior of the Active Pharmaceutical Ingredient Potassium Guaiacol-4-sulfonate. Cryst Growth Des 2013, 13, (7), 3028-3035.

35. Redlich, O.; Kister, A. T. Algebraic representation of thermodynamic properties and the classification of solutions. Ind. Eng. Chem. 1948, 40, (2), 345-348.

36. Kuznetsov, G. M.; Leonov, M. P.; Lukyanov, A. S.; Kovaleva, V. A.; Shapovalov, M. P.

Description of Liquidus Curves of Chemical Compounds Ambn. Dokl Akad Nauk Sssr+ 1975, 223, (1), 124-126. 